\title{
Managing interdependencies in supplier networks
}

\author{
Catarina Roseira $^{\mathrm{a}, *}$, Carlos Brito ${ }^{\mathrm{a}, 1}$, Stephan C. Henneberg ${ }^{\mathrm{b}, 2}$ \\ ${ }^{a}$ Faculty of Economics, University of Porto, Rua Dr. Roberto Frias, 4200-464 Porto, Portugal \\ ${ }^{\mathrm{b}}$ Manchester Business School, University of Manchester, Booth Street West, Manchester M15 6PB, United Kingdom
}

\section{A R T I C L E I N F O}

\section{Article history:}

Received 22 May 2009

Received in revised form 11 April 2010

Accepted 19 May 2010

\section{Keywords:}

Supplier network

Supplier interaction

Cross-over effect

Supplier management

\begin{abstract}
A B S T R A C T
Building and managing a supplier base has been referred to in the literature as a key aspect of supplier management. Scholars have proposed a number of models aimed at enhancing the effectiveness of supplier network management, mainly based on a portfolio approach. In the IMP tradition of research, those models are often criticized as they ignore the interdependencies between the different existing dyadic relationships of a focal buyer company and its suppliers. Such interdependencies are the main focus of this paper, which has four objectives: (1) To analyze the types of relationships linking suppliers, (2) to understand the factors and dynamics underlying the creation and management of these relationships (3) to uncover existing links between buyer-supplier and supplier-supplier relationships, and (4) to clarify how different configurations of supplier relationship interactions impact on the performance of the actors involved. The paper discusses two empirical case studies, using the supplier networks of two focal buyer companies. We find that supplier interdependencies are mainly a by-product of the buyer-supplier dyads. Furthermore, the nature and dynamics of these dyads are a strong determinant of the scope and frequency of supplier connections and the corresponding effects on performance.
\end{abstract}

(c) 2010 Elsevier Inc. All rights reserved.

\section{Introduction}

Globalization and specialization processes have led to the intensification of competition in most industries (Harland, Lamming, \& Cousins, 1999). In order to cope with such challenges, companies tend to reassess their competitive positioning by specializing around their core capabilities and resources, and by buying or mobilizing other resources from a network of customers (Ford, Gadde, Håkansson, \& Snehota, 2003) and suppliers (Cousins \& Spekman, 2003). In such an environment of resource dependencies (Pfeffer \& Salancik, 1978; Casciaro \& Piskorski, 2005), purchasing decisions gain growing importance, giving supply management a strategic character (Gattorna \& Walters, 1996). The resulting supplier networks encompass diverse companies with different fit vis-àvis the buyer company's context and its strategic intent. As a consequence, managing supplier networks involves not only the individual dyadic relationship with single suppliers but the entire set of supplier relationships, including the interdependencies between them. Traditionally, supplier portfolio models have been used to represent supply relationships. However, although empirical studies have shown that such models enjoy a high reputation among practitioners (Wagner \& Johnson, 2004;

\footnotetext{
* Corresponding author. Tel.: + 351225571170.

E-mail addresses: croseira@fep.up.pt (C. Roseira), cbrito@fep.up.pt (C. Brito), stephan.henneberg@mbs.ac.uk (S.C. Henneberg).

${ }^{1}$ Tel.: +351225 571170

2 Tel.: +441613063463.
}

Gelderman \& van Weele, 2005), they have been received with skepticism by academics. In particular, research within the tradition of the IMP Group (cf. Håkansson \& Ford, 2002; Ford \& Håkansson, 2006) has been critical of these portfolio models' lack of an integrative view, e.g. by not taking into account supplier interdependencies (Dubois \& Pedersen, 2002).

Thus, the challenge is to understand the complexities, and particularly the interdependencies which are related to multiple supplier relationships existing within the portfolio of a buying company. Of special interest for our research is the question of how these interactions come about, how far the focal buying company is involved in these interactions, and how they impact on the different dyadic buyer-supplier relationships as well as on supply management performance. Thus, we aim to investigate the nature, creation, dynamics, and effects of supplier interdependencies within the supplier network of a focal buyer. A better understanding of these issues will clarify the potential benefits, but also the limitations of supplier connections and the cross-over effects on firms' performance resulting from interdependencies of supplier business relationships. Our contribution is therefore particular to the area of uncovering different structures of supplier interdependencies beyond the more simplistic explanations provided by portfolio models.

The article is divided as follows: after this introduction, the second section addresses supplier networks both from a portfolio perspective and a network perspective. This is followed by a discussion of the methodology of the research project, and a description of the empirical cases. Findings and finally discussions of the main theoretical and managerial contributions drawn from our research will conclude this article. 


\section{Conceptual background}

The context of purchasing management in an industrial setting has been changing, moving from the 'simple' outsourcing of production and supply of resources as part of the 'sorting decisions' of a company (Alderson \& Martin, 1965) to complex decisions about higher level and value-adding services, such as design and product development (Gadde \& Håkansson, 2001). As a consequence, companies buy different resources (e.g. products, knowledge, brands, reputation) from different suppliers in order to transform and integrate them (Pfeffer \& Salancik, 1978; Casciaro \& Piskorski, 2005). In this context, the specifics of the supplier base are considered the cornerstone of supplier management. Therefore, in order to provide the conceptual background for our article, the extant literature on supplier portfolios is briefly surveyed, emphasizing main strengths and limitations. This leads to the introduction of a network perspective which will serve as the conceptual anchor for understanding the interdependencies between supplier relationships.

\subsection{Understanding and managing supplier networks as portfolios}

The concept of a 'product as a network entity' is used as a metaphor for the interconnectedness of actors, activities and resources needed to create a single offering (Dubois \& Pedersen, 2002). It also emphasizes the increasingly important role that suppliers play in the success of a buying company (Wagner \& Johnson, 2004). Inasmuch as the type of resources and activities integrated in an offering and the degree of exploitation vis-à-vis exploration are different, the organization of resource access and mobilization must also be different (Loasby, 1998; Araújo, Dubois, \& Gadde, 1999, 2003). There exists no ideal buyersupplier relationship type to achieve this, and the determination of what constitutes an optimal supplier relationship is by its very nature contingent upon many factors (Ford et al., 2003). Companies must therefore decide what relational strategy to adopt with each supplier and how to allocate resources among supplier relationships (Ritter \& Ford, 2004).

One solution to this problem is proposed in the form of selective portfolio strategies to reach 'optimum' supplier relationships based on identifying which suppliers should be interacted with in a more intensive way, and which should be managed in a less intensive way (Wagner \& Boutelier, 2002; Wagner \& Johnson, 2004). Such portfolio models were introduced as a tool to manage a balanced combination of supplier relationships best serving the long-term interests of the buyer company (Turnbull, 1990). The first major conceptual development in this area was Kraljic (1983) matrix. Its goal was to minimize supply risks and maximize the buying company's bargaining power. The departure point of Kraljic's matrix relates to two variables: product relevance and supply risk. Each purchasing item is analyzed according to these two criteria and consequently placed in one of four categories. Companies then analyze their bargaining power vis-à-vis the suppliers, identify areas of opportunities or vulnerabilities, evaluate supply risks, and set resulting purchase strategies for each matrix category (e.g. explore or diversify sources of supply) (Kraljic, 1983). This matrix model was widely accepted by managers and is considered even today as the standard in the field of purchasing (Gelderman \& van Weele, 2005).

Other portfolio models have been developed since then, focusing on clients (e.g., Turnbull \& Zolkiewski, 1997), on suppliers (e.g., Olsen \& Ellram, 1997; Bensaou, 1999; Nellore \& Söderquist, 2000; Hartmann, Ritter, \& Gemünden, 2001; Gelderman \& van Weele, 2002) or generally on business relationships (Krapfel, Salmond, \& Spekman, 1991; Zolkiewski \& Turnbull, 2000). These matrix models vary in terms of the factors, factor weights, or number of analysis steps. The choice of variables represents the cornerstone of portfolio models and is quite problematic. Problems concerned with choosing the most suitable variables, measuring them properly, and the inclusion of environmental factors have been discussed as major limitations (Nellore \& Söderquist, 2000; Zolkiewski \& Turnbull, 2000). Furthermore, Dubois, and Pedersen (2002) argue that portfolio matrixes constitute an oversimplification of reality, and they question the possibility of defining business strategies based on this type of tool.

Furthermore, portfolio models assume suppliers as passive actors (Gelderman \& van Weele, 2002), disregarding the fact that the implementation of a supply strategy is contingent on the joint efforts of the buyer company as well as the suppliers (Axelsson, 1992; Hartmann et al., 2001). Thus, besides identifying critical suppliers (which is arguably possible via portfolio models), managers still face the challenge of mobilizing these suppliers (Mouzas \& Naudé, 2007) for which portfolio models do not provide guidance.

The point of departure for this article relates to the inherent limitations of portfolio models from an interaction perspective: as Dubois, and Pedersen (2002) state, portfolio and matrix models are static since they do not take account of the dynamism, particularly the interdependencies between suppliers, inherent in interaction processes underlying business relationships. Portfolios treat buyersupplier relationships as isolated dyads which constitute the unit of analysis by applying an 'optimization perspective', thus they do not capture all ranges of possible interactions (Zolkiewski \& Turnbull, 2002). The interdependence between supplier relationships is restricted to the optimal allocation of buyer's resources to each of these supplier relationships. This means that other interdependencies and contingencies between the many different supplier relationships are ignored, even if these could produce substantial benefits for the companies involved (such as economies of scale, or coordination efficiencies) (Dubois et al., 2004). For instance, as Dyer and colleagues have shown, Toyota has long recognized the benefits of learning via sharing knowledge with its suppliers and of stimulating the sharing of knowledge between the suppliers themselves (Dyer \& Nobeoka, 2000; Dyer \& Hatch, 2004).

In a similar vein, Håkansson, Havila, and Pedersen (1999) claim that a supplier has a higher probability of learning and innovating when connected with the buyer's other suppliers. Inasmuch as competitive advantages are more and more linked to interorganizational learning (Dyer \& Nobeoka, 2000), treating supplier relationships as isolated dyads risks limiting the buyer's as well as the suppliers' possibility of exploring their full potential. Therefore, a network perspective, based on an interaction model which takes the existing interdependencies between business relationships into account, needs to be employed (Ford \& Håkansson, 2006). This means broadening the dyadic buyer-supplier interaction at least to triads, i.e. buyer-supplier-supplier relationships (Phillips, Liu, \& Costello, 1998; Choi \& Wu, 2009).

In summary, supplier portfolio management based on a matrix rationale to define with which suppliers a focal buyer should interact, in what way, and how it should manage its supplier relationships with them according to its strategic goals, has been criticized for different reasons (Wagner \& Johnson, 2004). However, for the purpose of our article the main shortcoming relates to the inability of portfolio models to take into account the network effects of supplier interdependence and indirect supplier relationships which affect the buying company. We posit that portfolio models provide neither a truly integrative network perspective of the interdependencies between supplier relationships nor a dynamic perspective of how relationships, capabilities and resources evolve within such triadic structures. Consequently, this makes it unavoidable to take suppliersupplier interdependencies into account.

\subsection{Supplier networks and the network perspective}

The need to use a network rationale, and its implicit criticism of portfolio models, has been demonstrated by the studies of Araújo et al. 
(1999) and Mota, and de Castro (2005) who show how the decisions concerning a specific client or supplier may affect the relationships with other clients or suppliers. Interdependencies within a portfolio are better analyzed through the association between the variety of supplier relationships, on the one hand, and the focal firm's strategy to use and develop relational capabilities, on the other (Sivadas \& Dwyer, 2000; Ma, Yao, \& Xi, 2009). The goals and perceptions of all relevant suppliers are equally important in this process. The importance of the direct as well as indirect effects that relationships may have upon each other has frequently been highlighted in the broader IMP literature (e.g., Håkansson \& Johanson, 1993; Ford \& McDowell, 1999; Holmen \& Perdersen, 2003). Thus, the characteristics and effects of each supplier relationship depend on their complementarity with the structure of activities and resources of the focal buyer company as well as its other supplier relationship partners (Håkansson \& Snehota, 1995). Horizontal supplier relationships are mutually (inter-)dependent, therefore cross-over effects due to network characteristics of the supply arrangements can be expected, which may or may not be intended, predictable, or positive for the buying company (Ford \& McDowell, 1999).

The existence of such cross-over effects means that to understand a buying company's supply relationships, the characteristics of the underlying triads (i.e. buyer-supplier-supplier relationships) need to be explored. For instance, improvements in product quality by a particular supplier may lead the buyer company to demand similar changes from its other suppliers (buyer-involved cross-over effects). Furthermore, different suppliers may share knowledge about a technological innovation in order to establish new product standards which improves their efficiency in dealing with a buyer company (buyer-independent cross-over effects). Anticipating and/or managing such cross-over effects may help the buyer company to minimize possible negative outcomes and maximize positive ones (the same holds true for the involved suppliers). Actively supporting supplier cooperation may result in better combinations of suppliers' resources and activity coordination, with benefits to the buyer as well as other actors in the supply network (Gadde \& Håkansson, 2001).

Managing such cross-over effects (i.e. fostering or limiting them) implies that one (or more) of the actors involved assumes an active role towards the other actors and the relationships that link them (Ford et al., 2003; Mouzas \& Naudé, 2007). Supplier portfolios therefore mirror findings by Holmen \& Perdersen (2003) and Havila, Johanson, and Thilenius (2004) about indirect business relationships in networks settings. Holmen \& Perdersen (2003) identified three functions of managing such interactions: relating, isolating, and mediating. A relating function in supplier portfolio management refers to networking activities by the focal buyer to bring different suppliers together by allowing them to relate directly. However, the buyer company may choose to intentionally isolate suppliers from each other (e.g., in order to play one against the other) (Ford et al., 2003). Furthermore, a mediating function can be postulated, i.e. the decision by the focal buyer to transfer certain resources (e.g. knowledge, processes) from one supplier relationship to another. According to Havila et al. (2004), these networking activities can happen in 'serial triads', where activities are performed in sequential dyads. Activities can also occur at the same time in 'group poliads', requiring the collaboration of all actors to develop shared activities.

Concepts of connectivity, dependency, and interaction are central to the IMP approach to explaining network characteristics (Ford et al., 2003; Ford \& Håkansson, 2006). Using a network perspective requires an understanding of the effects that supplier relationships and their interaction processes have upon each other (Araújo et al., 1999; Ford \& McDowell, 1999; Dubois \& Pedersen, 2002; Mota \& de Castro, 2005). One crucial aspect relates to understanding horizontal relationships between suppliers and how buying firms perceive and try to influence these relationships. Buyer-dependent cross-over effects can be distinguished from buyer-independent ones, depending on the involvement of the buyer in horizontal supplier relationships. It remains unclear how these relationships and cross-over effects (if they do exist) are established, developed and coordinated, which strategic goals they respond to, and the role of different actors in instigating and developing such horizontal supplier relationships. Considering the interactive and contingent nature of business relationships it seems unreasonable to expect that horizontal supplier relationships can be 'decided' and implemented unilaterally by one company (be it the buyer or one of the suppliers); rather one would expect them to be co-determined by several actors involved.

Focusing on horizontal relationships, Easton, and Araújo (1992) and Easton, Burrell, Rothschild, and Shearman (1993) suggest that cooperation on the one hand, and conflict on the other, must be regarded as the ends of a continuum of 'co-relation' possibilities between suppliers. The authors offer a typology which includes five main categories of relationships within that continuum: conflict, competition, coexistence, cooperation and collusion. Conflict arises when firms seek to destroy or incapacitate their competitors. Competition, the second main category, encompasses those strategies defined to achieve a sustainable competitive advantage. Coexistence happens when different suppliers are independent or perceive themselves as independent. Cooperation occurs when firms work together towards a common perceived objective. Finally, collusion can be regarded as a particular case of cooperation. It arises when competitors cooperate in order to injure a third party. A similar typology of horizontal relationships is suggested by Bengtsson, and Kock (1999). However, these typologies refer to relationships between suppliers in competition; thus, horizontal relationships of a non-competitive nature are not considered, therefore leaving room for further research in supplier networks.

While this paper is not about dyadic buyer-supplier relationships per se, nor about how they should be differentiated in order to optimize resource investments, dyads cannot be ignored within the triadic perspective. They constitute an essential component of the context where direct and indirect connections between suppliers within a supplier network are created. Furthermore, inasmuch as one of the major flaws of portfolio models is the disregard for the complementarities and interdependence of dyadic relationships, the analysis of such issues requires some basic understanding of supplier dyads, namely their strategic goals (e.g. efficiency or innovation), their technical interfaces (standardized, specified, translated or interactive) (Araújo et al., 1999), and the different actors' perceptions and attitudes (Henneberg, Mouzas, \& Naudé, 2006). In the same sense, it is conceptually impossible to separate the dynamics of the immediate tier-one supplier network from the wider network in which the buyer and the suppliers are embedded in. Thus, while the unit-of-analysis will be the limited network consisting of a focal buyer company and its direct supplier network, some knowledge of the expanded network and the way it affects the buyer-supplier-supplier relationships at hand is necessary in the analysis.

\subsection{Supplier networks: some research questions}

Authors from the IMP group are prescriptive about the need to evaluate and eventually manage the effects that supplier relationships and their interaction processes have upon another (Araújo et al., 1999; Ford \& McDowell, 1999; Dubois \& Pedersen, 2002; Mota \& de Castro, 2005). Nonetheless, studies going beyond a collection of dyadic relationships and taking an integrated view on their connections and interdependencies are still scarce (cf. Araújo et al., 1999; Ford \& McDowell, 1999; Mota \& de Castro, 2005; Choi \& Wu, 2009), leaving room for further research on how firms coordinate, influence and mobilize supplier portfolios. More specifically, the extant literature does not help us understand how horizontal supplier relationships (and resulting cross-over effects) are established, developed and coordinated, the goals they respond to and the roles of the parties involved. Considering the interactive nature of 
relationships, it seems unreasonable to expect that they can be 'decided' and implemented unilaterally by a company; rather one would expect them to be co-determined by the actors involved.

In short, the main goal of this article is to explore the interactive structure and dynamics of supplier networks. Three main research foci emerge:

(1) What types of interdependencies and cross-over effects exist within supplier networks?

(2) How do such interdependencies emerge and develop?

(3) What is the impact of those interdependencies and how are they perceived by the actors involved?

\section{Research methodology}

In order to come up with an accurate description of the interdependencies and complexities of relationships in supplier networks, a case study approach was adopted, allowing for a multilevel investigation covering the buying companies' relationships with their first-tier suppliers and the supply network itself (for a comprehensive discussion of the use of case studies in interorganizational research see Andersen \& Kragh, 2010; Easton, 2010; Jårvensivu \& Törnroos, 2010). Bonoma (1985) and Dubois, and Araújo $(2004 ; 2007)$ argue that case research is likely to provide a significant contribution to the development of theory in the fields of purchasing and supply management. Boundary issues, temporality as well as the dynamic nature of relationships can be captured via such a case study method.

Two industrial firms were selected as focal buyers (Vulcano in the boiler manufacturing industry, and Adira in the mechanical engineering sector). Empirical data was collected through 62 semi-structured interviews (lasting 1 to $3 \mathrm{~h}$ each). Interviews were held in the interviewees' companies and were followed by a visit to the premises. The interviewing process included different supply-related top and middle managers (covering functions such as business development, engineering, production, quality, procurement, purchasing and logistics) from these two focal companies (14 respondents in total). 31 suppliers were also interviewed (18 from Vulcano and 13 from Adira), leading to the analysis of 31 buyer-supplier dyads. The supplier selection and interviewing focus followed a progressive logic; the set of suppliers was identified according to two main criteria: their perceived importance to the focal buyer, and the longevity of buyer-supplier relationships in order to capture the change processes over time. This resulted in dyads ranging from two to 50 years old. Buyer-supplier relationships were used as the initial focus of the data capture, followed by a study of the links between suppliers, as well as the nature of the buyer's involvement in those supplier relationships. In this way it was possible to progressively map existing buyer-supplier and supplier-supplier relationships and to build up a supply network view. This process resulted in the identification and analysis of 22 horizontal supplier-supplier dyads. Suppliers were also questioned about other suppliers to the focal company with whom they did not interact, thus allowing a wider view of the supplier network. The different dyadic relationships (between buyer-supplier as well as supplier-supplier) were also used to analyze the cross-over effects. The collection and analysis of data followed a configuration analysis process proposed by Ragin (2000). Each case (i.e. one focal buyer and its supplier network) was analyzed separately in order to understand how the various themes combine in an integrated and coherent configuration, followed by a comparative analysis of the two cases in order to identify and explain their (dis) similarities. Data was collected mainly through the interviews, but other sources such as websites, internal documents, press articles and visits to the firms' premises were also used to complement and triangulate data (Dubois \& Gadde, 2002). Triangulation was also achieved by contrasting the views of multiple interviewees. All interviews were taped, transcribed and sent to the interviewees for possible corrections. Data was content analyzed according to categories and themes derived from concepts identified in the literature review in order to enhance internal validity (Krippendorff, 2004).

\section{Supply networks case studies}

\subsection{Case study 1: Vulcano}

Vulcano is a Bosch manufacturer of gas-fired hot water boilers, and constitutes Bosch's Competence Center in this product area. Since its foundation in 1977, the company's success has depended on its ability to forge links with external actors, especially suppliers, to add value to the activities performed in-house. It invests in external relationships that allow it to "integrate suppliers' capabilities as if they were ours". In the past, Vulcano has specified all details for sourced parts (such as functions, materials and dimensions) and suppliers manufactured them to these specifications. In recent years, however, Vulcano's development team has been actively seeking suppliers' assistance in developing such parts, especially in areas where it does not possess sufficient production or knowledge capabilities and does not want to develop them itself. Thus, Vulcano expects all suppliers to "proactively produce and suggest new solutions in terms of product specifications, materials or processes". To make participation of suppliers possible, technical interfaces with suppliers are generally interactive. Additionally, suppliers' relationships with other clients are seen as a source of diversity that is perceived positively by Vulcano.

Fig. 1 depicts the existing relationships between Vulcano and its suppliers included in the study. Some of these suppliers belong to the same specialization or competitive groups: plastic parts (Mas, Mis, Sp and Tpe); stamped metallic parts (Ic and Si), injected metallic parts (Fd and $\mathrm{Sn}$ ); steel and other metals ( $\mathrm{Gv}$ and $\mathrm{Sl}$ ); turned parts ( $\mathrm{Gn}$, To and USA). It is noteworthy that fourteen of these suppliers have horizontal supplier-supplier links with each other, with or without the involvement of the focal buyer Vulcano. Furthermore, thirteen suppliers know who their direct competitors are in their business relationship with Vulcano. However, this information is not transmitted by the focal buyer, rather it is a characteristic of the close-knit industry where competitors normally know each other, i.e. form a 'competitive group' (Bogner \& Thomas, 1993; Fiegenbaum \& Thomas, 1993). Despite the abundance of inter-supplier links, most suppliers state that they feel no need to know specifically the other suppliers whose parts are technically connected with what they provide to Vulcano. Any technological adaptation necessary is dealt with as part of the supply relationship with Vulcano and not within horizontal supplier relationships. Thus, Vulcano plays an isolating role (Holmen \& Perdersen, 2003), which is perceived to be an effective way to coordinate suppliers. If links between suppliers exist, they are therefore often influenced by Vulcano, thus constituting indirect and buyer-involved cross-over effects between suppliers in the network. The horizontal supplier relationships are a result of, and are to some extent controlled by, activities by Vulcano. The majority of the seven supplier-supplier relationships which are outside Vulcano's sphere of influence (i.e. they represent buyer-independent and direct cross-over effects) link two suppliers of steel and other metals (Sl and GV in Fig. 1) to suppliers that use those raw-materials in their products. There are also two cases (SI-IC and SN-FD) in which one firm (IC and FD, respectively) had already supplied parts to the other (SI and SN, respectively) as subcontractors prior to their involvement with Vulcano. In fact, IC and FD were introduced to Vulcano by SI and $\mathrm{SN}$, in a situation when they themselves were not able to keep up with the rising demand from Vulcano. Despite the joining role (Holmen \& Perdersen, 2003) initially played by SI and SN and the fact that Si-IC and SN-FD are competitors, all the actors involved believe that the relationships between Vulcano and these suppliers are completely 


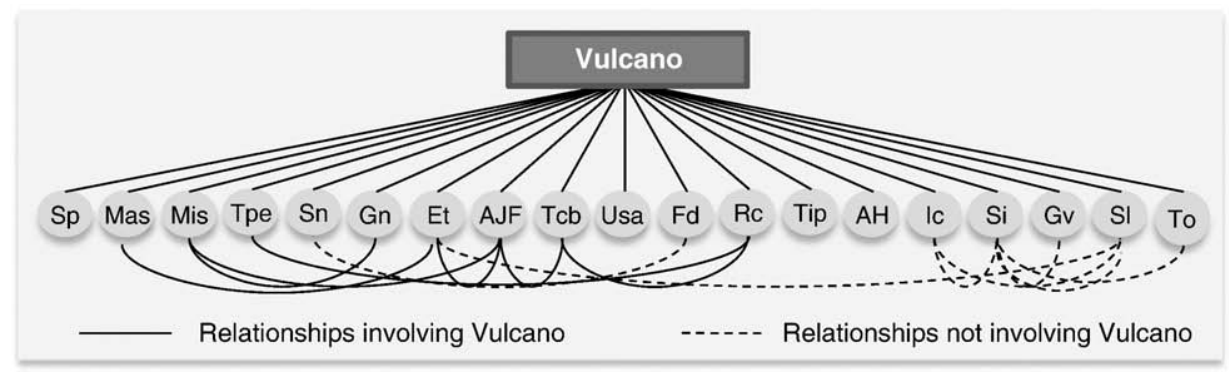

Fig. 1. Vulcano's supplier portfolio.

independent from the relationship that exists between the suppliers themselves, thus ossifying Vulcano's role as lynchpin of the supplier network.

Relationships involving Vulcano are all very similar, thus, only one of these cases is analyzed in detail. AJF is an electronic manufacturer of alarm systems. It was selected by Vulcano to develop and manufacture a remote control for one of its gas-fired hot water boiler models. AJF developed and specified all the electronic parts of the remote control and selected the sub-suppliers in this area. As the company does not possess the resources and capabilities needed to manufacture core non-electronic parts of this component, such as the plastic case, cables and LCD screen, it had to buy them from other companies. Despite the fact that AJF was responsible for the overall component project, it did not intervene in the development of the non-electronic parts or in the selection of the respective sub-suppliers (which were also direct suppliers to Vulcano). In fact, all these parts were specified by Vulcano or co-developed by Vulcano's current suppliers, with Vulcano negotiating the supply terms of these parts procured by AJF. When the developing and test phases were completed and regular production began, AJF assumed the leadership in the management of relationships with the second-tier suppliers of all the parts.

This solution, i.e. Vulcano controlling the different supply relationships in the initial phase after which the operational control is handed over to AJF, is considered by Vulcano as well as by AJF to be beneficial for all parties. It is based on a shared understanding of the complementarities between both firms' specific capabilities and existing network connections. Vulcano uses suppliers with adequate performance which are known to it, thus accelerating the process of developing and testing the various parts. AJF on the other hand achieves benefits that would be impossible without the association with Vulcano, e.g. lower purchase prices for the parts, reduced time and costs of selecting and auditing different suppliers. Furthermore, due to the fact that the focal buyer was responsible for the selection of AJF's second-tier suppliers, it makes it easier for AJF to press Vulcano to intervene if problems should arise (especially because these suppliers to AJF are also in direct supply relationships with Vulcano). Some suppliers therefore assume the double role of first-tier (to Vulcano) and second-tier suppliers (to AJF). Inasmuch as the critical activities (e.g. specification and negotiation of terms) are undertaken through the leadership of Vulcano, the inter-supplier relationships are restricted to the operational issues of managing orders (such as logistics and payments) that are perceived as less important. The fact that the sales to the other suppliers are only a small portion of their sales to Vulcano also contributes to this perception.

In the past, Vulcano has unsuccessfully tried to develop further relationships and buyer-dependent cross-over effects between its suppliers. For example, at one point it tried to persuade GV (one of its two suppliers of steel) to expand the conditions and terms granted to Vulcano to all the other Vulcano suppliers that use the same rawmaterials. Some of these suppliers already bought metals from GV but at a higher price. The benefit to Vulcano and its suppliers was clear: a reduction in raw-material costs would reflect on the costs of parts supplied to Vulcano. However, GV was of a different opinion, as
Vulcano's request would inevitably result in a reduction of GV's margins. While this loss could be offset by the reinforcement of the supply relationship GV has with Vulcano, GV was very reluctant to accept this agreement, and ultimately declined to do so. In other failed mediating experiences, Vulcano tried to bring several of its first-tier suppliers together to develop technically connected parts. However, although some suppliers did mention that such contacts had existed, they were unable to explain how and why they were initiated and later terminated, and who was involved. Neither Vulcano nor the suppliers seem interested in repeating or expanding these experiments of further horizontal supplier-supplier integration via buyerdependent cross-over effects, and the Vulcano-supplier dyads are still seen by most participants in the supply network as the best relational governance for innovation and adaptation processes.

Compared to buyer-dependent cross-over effects, indirect interactions (i.e. buyer-independent cross-over effects between different Vulcano-supplier dyads) are quite frequent and arguably very relevant, although they are not perceived by the actors to represent a key characteristic of the supply network. These horizontal interactions are mostly related to pricing issues, supplier capabilities (e.g., technical or logistical), and the diffusion of product or process innovation as well as best-practice routines. Most Vulcano-supplier interfaces are interactive, and many new solutions and innovations are either supplier-based or are co-created with suppliers. When new solutions produce relevant positive effects, this knowledge is diffused via the interactive interfaces to other first-tier suppliers in order to multiply its benefits. This diffusion is in fact mandatory if it relates to changes in parts bought under dual sourcing agreements. In one specific situation, a Chinese manufacturer proposed an innovation relating to the design of one part; this option was tested and resulted in superior performance in the use of raw-materials and manufacturing process issues. Consequently, the knowledge about this innovation was communicated to a Spanish manufacturer (Rc in Fig. 1) who supplied the same part to Vulcano. Thus, while these represent buyer-independent cross-over effects, they are nevertheless facilitated by the interactive nature of the different Vulcanosupplier relationships (Table 1 ).

Such indirect cross-over effects can also relate to pricing, or changes in capabilities. Price is an important factor when selecting a supplier for a new part or when renegotiating supply terms. Vulcano does not bargain about prices or use alternative supplier bids to force suppliers to cut prices. However, every two or three years, Vulcano

Table 1

Causes of changes on current Vulcano suppliers' positioning.

\begin{tabular}{ll}
\hline $\begin{array}{l}\text { Changes in supplier's balance } \\
\text { (rival suppliers only) }\end{array}$ & $\begin{array}{l}\text { Structural reconfiguration (rival and } \\
\text { non-rival suppliers) }\end{array}$ \\
\hline - Reduction of prices and other efficiency & $\begin{array}{l}\text { - Developing of new capabilities and } \\
\text { activities, leading to the } \\
\text { related investments } \\
\text { - Improvement of logistical and quality } \\
\text { reconfiguration of the portfolio } \\
\text { - Introduction of new suppliers }\end{array}$ \\
\end{tabular}


monitors the markets in order to compare current suppliers to potential ones, especially regarding pricing. According to Vulcano, this activity forces suppliers to constantly consider how they can become more productive in order to strengthen their relative positioning visà-vis rival suppliers. Thus, Vulcano's monitoring activity, together with the fact that it is open about these activities with its suppliers provides the structural prerequisites for indirect supplier-supplier cross-over effects.

Logistics is another area where cross-over effects can be seen. Logistics routines (e.g. order processes, production and delivery plans) adopted by Vulcano with one supplier are often replicated with other suppliers, even in different product groups, e.g. by non-rival suppliers. However, this replication is easier in relationships with otherwise competing suppliers that normally have similar production resources and processes. On the other hand, all suppliers are informed of the average supplier performance in these areas. As logistics accounts for about one third of the suppliers' evaluation done by Vulcano, this information serves as an internal benchmark within the supply network, and is thus a strong incentive for suppliers that are falling below the average to improve their performance.

The evolution of individual suppliers' resources and capabilities has had a strong impact on the evolution of their relationships with Vulcano. Changes in one supplier or changes in the resulting relationship with Vulcano have a more or less profound impact on several other first-tier suppliers, i.e. changes spill over within the supply network. Some of these buyer-independent cross-over effects are negative. For instance, investments resulting in efficiency gains (e.g. by buying equipment with higher productivity) may result in the reduction of purchases by Vulcano from less efficient suppliers (i.e. competitive or conflicting relationships between suppliers result). However, if suppliers improve their performance to match the new supply network benchmark, they may recover their previous position. Similarly, if a supplier invests in new and more value-adding activities (e.g. new product development), its supply relationship with Vulcano may be substantially altered, for example by changing its position within the supply network vis-à-vis Vulcano through becoming a preferred supplier in new projects. The development of new capabilities and activities may also lead to the reconfiguration of the supply network itself, as in the case of AJF which became a preferred first-tier supplier, while other Vulcano suppliers were subsequently relegated to second-tier status under the operational control of AJF.

\subsection{Case study 2: Adira}

Adira, founded in 1956, is the Iberian leader in tool-machinery manufacturing. Adira strongly believes that its success is based on its internal set of capabilities, and suppliers are perceived to have only limited relevance for its value creation process. This belief is reinforced by Adira's view of its suppliers as generally having very limited technical capabilities. Consequently, Adira prefers to have proprietary control over resources rather than to make use of external resources. The machines are entirely developed and designed by Adira and the same is true for the specification of all sourced parts, components, and materials. The company has two main types of suppliers: catalogue suppliers and subcontracted suppliers. Catalogue suppliers range from multi-brand parts wholesalers to national agents or local subsidiaries of multi-national firms such as Bosch or Siemens, selling standardized parts and components. Subcontracted suppliers range from small to medium-size firms that manufacture parts according to Adira's specifications. Adira uses both groups of suppliers to pursue efficiency benefits - lower costs, higher flexibility, and sourcing risk reduction, i.e. availability - and quality benefits. Catalogue suppliers are managed through standardized interfaces, and subcontracted suppliers through specified ones (Araújo et al., 1999). In both cases, Adira generally believes that it controls and dominates the relationships and subcontracted suppliers agree with this view.
Fig. 2 depicts Adira's first tier supply network. Subcontracted suppliers (MA, MS, CS, TS and JRM) are rival, small to medium-size firms that manufacture parts according to Adira's specifications. Four of them (MS, CS, TS and JRM) are heavily dependent on Adira's purchases and have few alternative clients. Eleven of the suppliers involved in the study know or are aware of other suppliers to Adira, and nine are involved in supplier-supplier interactions. Such reciprocal knowledge results from the characteristic of their industries or from information involuntarily provided by the focal buyer (e.g. mixed-up orders or simultaneous delivery windows). Such knowledge about competitors is generally unintentional on Adira's part, and is perceived as of low information value by all the actors involved. In fact, both Adira and the suppliers themselves feel that direct relationships between suppliers are unnecessary. Since the focal buyer specifies all the parts, suppliers do not need to have direct contact with each other, even in cases where they are producing interconnected parts. The suppliers generally state that they do not have much knowledge about any of Adira's other supplier relationships and that they feel no impact from those relationships. Intersupplier horizontal relationships developed outside of Adira's involvement are not very prevalent in this supply network. With the exception of the steel distributor FR (see Fig. 2) which sells to several other supply network members, suppliers do not see themselves as buyers from or suppliers to each other. In any case, those relationships that do exist (e.g. in FR's case) are seen as totally independent from Adira, and thus as having no perceived relevance on the supply relationships with the focal buyer.

As stated, inter-supplier relationships with the involvement of Adira (i.e. buyer-dependent cross-over effects) are rare. In fact, two of the cases depicted in Fig. 2 were terminated during the data collection phase. In one triad, MC supplied Adira with electronic components while sourcing parts (electric transformers) from EL. MC played a logistical and administrative role in this triad: taking care of order and delivery management, invoicing and payments. For this, MC received a commission. Prices and product specification were set by Adira and EL. However, MC was frequently ignored by Adira; EL was contacted directly in order to discuss technical issues and to place and pick-up urgent orders. As MC was eventually seen by both Adira and MC to add costs rather than value to their relationship, it was cut out of this relationship, and Adira and EL formed a direct dyad.

A similar case of disintermediarization relates to GC (Bosch's national representative in Portugal). Adira bought hydraulic valves from Rexroth and other components from GC. When Bosch bought Rexroth, GC became its representative, too. As buying valves from GC would have been very expensive, Adira continued to buy them from Rexroth with GC receiving a commission to take care of logistics, orders and payments, and to provide technical support. Adira perceived GC's technical capabilities to be very poor and claimed that it only worked as a 'mail box' and a 'buffer' between Adira and Rexroth. During the completion of the research project, BoschRexroth (BR) changed its international sales strategy and promoted the joint management of the Spanish and Portuguese markets. In this process, GC lost country sales representation to a Spanish affiliate of Bosch-Rexroth and its intermediation role was consequently terminated. However, GC still sells Adira other hydraulic components and technical support.

In another case of supplier interactions, Pol makes surface treatments for metallic parts and supplies Adira as well as some subcontracted suppliers. Prices and supply terms are negotiated with Adira. Part suppliers transport the parts to Pol, and after the treatment they pick up the parts and deliver them to Adira. Adira could easily concentrate all the suppliers' parts and be the sole client of Pol, but the current arrangement enables it to cut costs by transferring logistic activities to subcontracted suppliers. As the subcontracted suppliers also get better prices from Pol, the overall costs for the parts are smaller for Adira. However, the relationships between Pol and the 


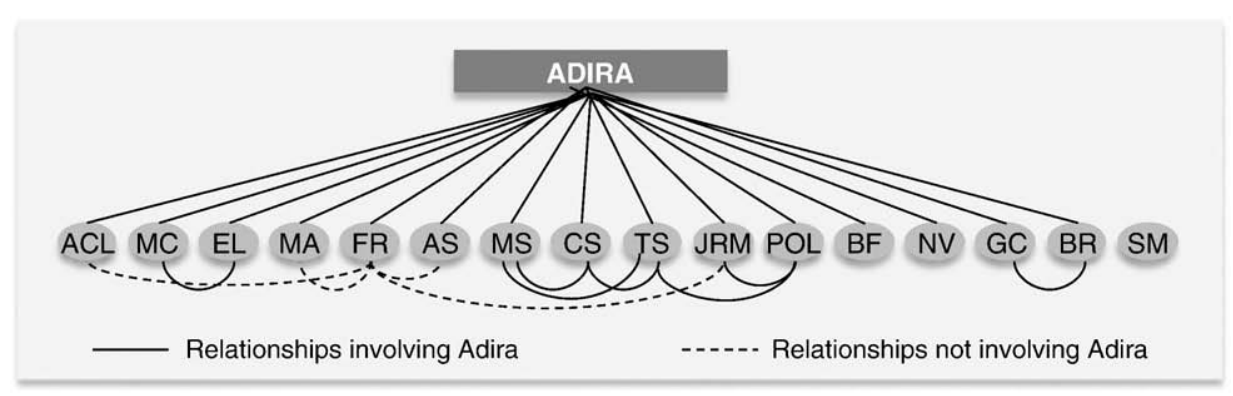

Fig. 2. Adira's supplier portfolio.

subcontracted suppliers are very tense and ripe with conflict. Due to the small sizes and short delivery lead times of Adira's orders, the costs of all involved suppliers are very high (e.g. due to transport or machine setup costs) and none of these suppliers is satisfied with the solution. The suppliers feel compelled to accept the supply relationship constellation due to their dependence on Adira's purchases.

Finally, suppliers MS, CS and TS, which are physically co-located, informally coordinate their deliveries to Adira. Each supplier has a specific delivery day defined by Adira. If an order is needed on a different day, one of the other suppliers will deliver the order together with its own. As the effects of this informal arrangement are seen as positive and reciprocal (delivery costs and lead times are reduced), all the involved actors are willing to continue this solution.

Indirect cross-over effects between different Adira-supplier dyads have a significant impact on this supply network, similar to the Vulcano case. Price represents an important dimension of these effects. For the catalogue suppliers, Adira compares the tenders, and prices are often renegotiated in order to force suppliers to cut them. In the case of subcontracted suppliers, Adira sets the prices for parts, and these are generally accepted (suppliers will inevitably lose the contract if they do not accept the set prices). Transfer of orders from one supplier to another is a frequent occurrence. Besides the price competition, the ability to respond to the frequent changes of Adira's production plans is also a determinant of cross-over effects in this context. In a small number of situations, Adira has reciprocity agreements with suppliers: Adira sells a machine to a supplier and in return it is obliged to buy from them a given number of parts. This may result in transferring the production of parts away from other suppliers until this volume agreement is fulfilled. Often such transfer of orders has a temporary effect, resulting in oscillations within the supply network: when the modalities are fulfilled (e.g. volume requirements), the regular supplier wins the order back. These occasional supply relationship transfers within the network are considered as 'normal business practice' and are accepted by all suppliers. Changes linked to suppliers' resources, on the other hand are of a more long-term nature. Suppliers that invest in more efficient machinery or processes will gain a higher share of Adira's purchases, shifting demand away from other suppliers. Even if this makes the less efficient suppliers dissatisfied, Adira's overall importance makes them reconcile themselves to those losses.

Table 2

Causes of cross-over effects on current Adira suppliers' positioning.

\begin{tabular}{|c|c|c|}
\hline Type of effects & \multirow{2}{*}{$\begin{array}{l}\text { Long-term effects in } \\
\text { suppliers' balance } \\
\text { (rivals) }\end{array}$} & \multirow{2}{*}{$\begin{array}{l}\text { Transitory effects in } \\
\text { suppliers' balance (rivals) }\end{array}$} \\
\hline Suppliers & & \\
\hline Catalogue suppliers & $\begin{array}{l}\text { Persistent problems of } \\
\text { prices and delivery lead } \\
\text { times }\end{array}$ & $\begin{array}{l}\text { - Prices } \\
\text { - Delivery lead times } \\
\text { - Reciprocity agreements }\end{array}$ \\
\hline Subcontracted suppliers & $\begin{array}{l}\text { - Evolution of resources } \\
\text { - Unsolvable conflicts }\end{array}$ & \\
\hline
\end{tabular}

Table 2 summarizes the most frequent cross-over effects evident in Adira's supply network. The causes of structural cross-over effects are different in the two groups of suppliers. In the case of catalogue suppliers, persistence of problems regarding prices and delivery lead times are the most important factors of supplier interaction effects with the involvement of Adira. However, in the case of subcontracted suppliers, prices are set by the focal company and delivery lead times are highly conditioned by the frequent changes that occur in its production plans. Thus, these factors are not the major factors of cross-over effects. Suppliers' investments in more efficient resources, on the other hand, represent the most determining causes of crossover effects. Exclusion of suppliers is rare, normally resulting from irresolvable conflicts due to disloyalty issues rather than from crossover effects created within the supply network. Transitory cross-over effects happen in the same way for both groups of suppliers. The main causes for them are price and lead time issues, as well as temporal reciprocity agreements.

\section{Analysis and results}

In this section, the findings of both cases will be discussed, specifically the types of interdependencies that exist in supplier portfolios, why and how they emerge and develop, and, finally, how focal buyers and suppliers perceive the impact of such interdependencies.

\subsection{Types of interdependencies and cross-over effects within supplier portfolios}

\subsubsection{Direct and indirect effects}

A variety of links between suppliers exist in both case studies of supplier networks, occasionally outside the sphere of influence of the focal buyers (buyer-independent cross-over effects). These links range from mere awareness of each other's existence, to social bonds, or to actual cooperative economic relationships. Such supplier relationships mainly relate to the logic of the supplying industry and are mostly perceived by the relevant actors as having no effect on their relationships with the focal buyers. With regard to the links between suppliers involving the focal buyer (i.e. buyer-dependent cross-over effects), two distinct types of links emerge: indirect links resulting from the cross-over effects of specific buyer-supplier dyads on other supplier relationships of the focal buyer, and direct links embodied in actual interactions between two or more suppliers. The most frequent occurrences are based on indirect links rather than on direct links between suppliers. The case studies indicate that both direct and indirect supplier interactions are predominantly focused on efficiency issues (such as prices and logistic processes). Direct supplier interactions play no role in innovation activities in the case studies (such as changing a product, or developing a new component); these issues are dealt with either by the focal buyer, by individual suppliers, or in individual buyer-supplier dyadic relationships. 
The cross-over effects in supplier networks are not homogeneously distributed along the supplier portfolio. One factor playing an important role in this context relates to the similarity of suppliers (e.g. exhibiting similar technical resources and capabilities, thus building specialization groups), as depicted in Fig. 3. As both focal buying companies use multiple sourcing strategies, they frequently interact with two or three suppliers with similar activities and resources, selling similar parts (e.g. suppliers of injected plastic parts). As would be expected, cross-effects (buyer-dependent as well as buyerindependent) are stronger in the groups of rival suppliers (i.e. the specialization groups), and weaker between them. The higher crossover intensity in the specialization groups relates to the most frequent cross-over effects which were identified, i.e. reduction of prices and transfer of orders that necessarily occur between alternative suppliers. Even when the buyer does not use alternative supply sources to force suppliers to cut prices, as in the case of Vulcano, suppliers feel that pressure and associate lost orders with their refusal or inability to follow their competitors' prices. Furthermore, the diffusion of innovation within supplier networks is easier within the same specialization groups. When production contexts and resources tend to be similar, the replication of changes of parts, quality procedures, productive processes, etc. is facilitated. However, despite context similarities, changes are sometimes hard to transfer between suppliers due to their tacit nature. These and other emerging problems are always dealt with in the direct buyer-supplier relationships.

Changes in the suppliers' industries are also a strong inducer of change. In both case studies, the pressure of focal buyers to obtain lower prices is fostered by a similar trend in suppliers' markets, highlighting the impact of environmental factors as suggested by Zolkiewski, and Turnbull (2002). Thus, price reduction tends to affect all suppliers due to this globalizing trend, even if it affects some supplier groups more severely than others. However, other aspects of change, for example those of a more specific nature such as the evolution in production equipment, have different impact on different groups. When efficiency is pursued through the indirect supplier links described, changes are usually contained in each specialization group of similar suppliers, and do not normally affect the overall structure of the supplier network in terms of actors, resources and activities. However, and less frequently, efficiency goals may require the reorganization of the whole supply network structure and the reconfiguration of different actors' roles, thereby leading to the establishment of direct interactions between suppliers.

\subsubsection{Competitive nature of interdependencies}

In both case studies, relationships between competitors mostly resemble the categories of competition and co-existence identified Easton and Araújo (1992), Easton et al. (1993) and Bengtsson, and Kock (1999). Competition is an outcome of the pressure suppliers feel to improve due to the focal buyers' explicit demands (or based on their own interpretations of implicit cues from the buyer, e.g. lost orders). Coexistence seems to exist when suppliers perceive their relationships

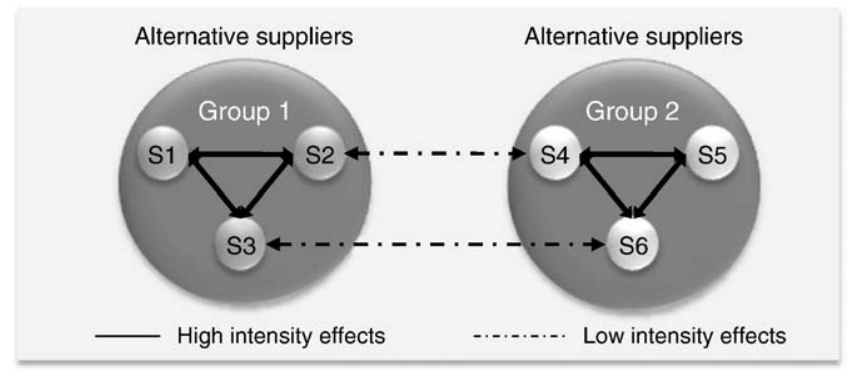

Fig. 3. Intensity of cross-over effects in supplier portfolios within/between specialization groups. with the focal buyer as independent from the other buyer-supplier relationships in the supply network. The prevalence of co-existence is higher in Adira's supplier network than in Vulcano's. Higher stability (e.g. relationship age, routinized activities, established network roles), less openness and interactivity of the (especially technical) interfaces between Adira and the suppliers, and individual supplier evaluation (no overall benchmarking) seems to facilitate supplier myopia to the potential impacts of their competitors' relationships with the focal buyer. Coopetition (Bengtsson \& Kock, 1999) is rare; the group of Adira's suppliers coordinating deliveries is the single example found in both case studies. Cooperation and conflict exist, although not usually between competing suppliers but between complementary suppliers. In both supplier networks, some suppliers are involved with each other in triadic structures (thus also involving the focal buyer), either as suppliers to each other (e.g. Vulcano-AJF-TPE and Adira-Po-JRM triads), or when suppliers intermediate the relationship between another supplier and the focal buyer (e.g. Adira-GC-BR and Adira-MC-EL). As expected, a minimal amount of cooperation is needed for these relational arrangements to succeed. While some conflict can also be expected in any business relationship, these arrangements can gain a conflictive nature when they are perceived as negative to the interests of one or more actors (as in the Adira-Pol-JRM triad) or when one or more actors are perceived as a low-value counterpart by the other triad participants (e.g. Adira-MC-EL).

\subsubsection{Nature, scope and intensity of cross-over effects}

Interdependencies may be based on similar resources used by suppliers to produce similar products, constituting alternative supply sourcing within specialization group. Changes in the resources of one supplier may result in an improved position, and consequently a weakened position of another supplier vis-a-vis the focal buyer. For instance, the investment in more efficient production equipment may result in lower prices and an increase of the quota of the buyer purchases in that specific category. However, if activities and products remain unchanged, the durability of the efficiency-related cross-over effects (cf. Tables 1 and 2) depends on the ability of suppliers to respond to their competitors' moves. If suppliers are unable to keep up with their competitors, changes in the suppliers' positioning (relative importance vis-à-vis the focal buyer) may become structural. However, they may be able to address these changes by making similar investments in more efficient execution and reverse this situation. In this case, changes of the suppliers' different positions in the supply network will only be transitory, until the 'weakened' supplier regains its position. Such resource-related changes translate to cross-over or indirect effects and their scope is normally limited to rival suppliers.

Interdependencies may also result from changes in the activities performed by the suppliers. Changes in activities are normally supported by the acquisition of new capabilities that are more costly to emulate than tangible resources. A change in the activities of a specific supplier may originate a change is its role within the supplier network. For instance, the investment in new activities may enable a manufacturing supplier to perform assembling activities previously executed by the focal buyer. A change in the structure of the supplier network will occur, as new relationships are formed between previously unconnected suppliers (e.g. assembly and parts suppliers). The scope of activity-related changes is wider than that of the resource-related ones, as it may result in improved positioning vis-àvis rival suppliers (indirect effects), and it may also affect non-rival suppliers that become counterparts.

Finally, actors can also be the source of change in supplier networks. Inclusion of new and more resourceful suppliers may lead to the loss of importance or replacement of existing ones. Perceived disloyalty on the part of suppliers is indicated in both case studies as the single reason for definitive elimination of a supplier by the focal buyer. While both aspects impact only on the competitors of the excluded or 
included suppliers, such actor-related changes are not a frequent driver of change, at least not in the two case studies analyzed.

\subsection{Emergence and development of interdependencies within supplier portfolios}

Cross-over effects in supplier networks can result in the diffusion of innovation (e.g. changes in parts, raw-materials or production processes), or more frequently in efficiency improvements (e.g. price reduction). The dynamics of the diffusion of such changes (efficiency or innovation) from one buyer-supplier dyad to another dyad (crossover effect) is conditioned by the roles actors play, as well as the type of relationship adopted by the various suppliers. As shown in Fig. 4, the origin of changes can be the suppliers (Model 1) or the buyer (Model 2). The adoption of relationships that foster supplier initiative and proactivity (e.g. with interactive interfaces) multiply the sources and frequency of changes and induce stronger dynamics in the supplier portfolio. Furthermore, when suppliers play an active role (Model 1), there is a higher potential for innovation that derives from the diversity of their idiosyncratic experiences with other actors, e.g. other buyers. Such a possibility of exploring diversity is severely reduced when the focal buyer dominates the relationships (as in Model 2), for example due to specified interfaces (Araújo et al., 1999). These findings are in line with Foss, and Loasby (1998), who have argued that the creation of knowledge (such as innovation) is fostered by the diversity of conjectures about new uses for existing resources, as is in the case of dynamic suppliers (e.g. Model 1 in Fig. 4), while strong control by the buyer diminishes that diversity and the possibility to innovate. As Loasby (1998) argues, control frustrates the development of capabilities that one might later wish to access.

A higher openness and interactivity of relationships within a supply network also contributes to higher awareness of supplier interdependence. As mentioned in Section 5.1.2, suppliers' myopia to the potential impacts of their competitors' relationships with the focal buyer is higher in the case of Adira than in the case of Vulcano. As Vulcano's suppliers are more aware of their interdependencies, they actively seek to protect or strengthen their positioning vis-à-vis other suppliers. Consequently, awareness of interdependencies feeds suppliers' initiatives to invest in new resources, capabilities, and activities and their response to buyer's requests regarding innovation or efficiency-related investments, as suggested by Dubois, and Fredriksson (2008). Despite these differences, the buyer plays a major role as a mediator between the suppliers in both case studies. In fact, both focal buyers (Adira and Vulcano) normally perform an isolation or mediation function (Holmen \& Perdersen, 2003), allowing them to induce buyer-dependent cross-over effects and to filter the effects that are transferred from one supplier to another according to their interests and goals.

When suppliers take on an activity previously performed by the buyer, e.g. assembly tasks, it normally implies the creation of triads involving suppliers of different specialization groups that execute dissimilar and close complementary activities in the production chain of the buyer's products. Their basic underlying rationale is linked to efficiency benefits, translated into lower costs of suppliers' products (reflected in suppliers' selling prices to the focal buyer) and more efficient logistics processes. In Vulcano's case, these arrangements also eliminate the need to audit and test sub-suppliers, reducing the time-to-market of new products. The analysis of the content and dynamic of these arrangements revealed that they are similar to the concept of serial triads (Havila et al., 2004), in that the actors do not interact with all the others at the same time or in the same way. Fig. 5 represents this situation. In these schemes, relationships are 'incomplete'. Each of them uses only a part of the resources and activities that normally exist in buyer-supplier relationships, working as a piece of a wider puzzle. In fact, the activities executed in buyersupplier relationships are different from those performed in the supplier-supplier relationships, corresponding to different phases of a 'classical' buyer-supplier relationship. This sequential organization is supported by the complementary and dissimilar activities of the several actors involved.

Activities such as specification of parts, new product development, or negotiation of supply terms are kept in the strict sphere of buyersupplier dyads (phase 1 in Fig. 5). Suppliers then coordinate the ordering/delivery of the parts/materials to the supplier (S2) in charge of the assembly or finishing of the component (phase 2); this product/ component is then later delivered to the focal buyer (phase 3). Thus, the coordination and exploration of the most complex and dynamic supplier capabilities is always performed by the focal buyer. Suppliers are responsible for the more operational activities, which are less dense in resources and supported mainly by static capabilities. These schemes allow suppliers to coordinate highly complementary and dissimilar activities (Richardson, 1972) while keeping relational processes close to transactional relationships with low interactivity and complexity. The more complex tasks of combining the resources and activities of suppliers (deciding who does what) is done less by direct supplier-supplier relationships but rather by their dyadic relationships with the focal buyer.

\subsection{Perceived impact of interdependencies on the actors involved}

In all the identified triads, one of the companies involved acts as an intermediary between the other companies. The focal buyer plays this relating function (Holmen \& Perdersen, 2003) when there are no previous economic interactions between the suppliers, facilitating the establishment of relationships. The value of the intermediary in the eyes of the intermediated firms seems to strongly condition the success of these relational schemes. In the triads that were dissolved during the empirical phase of this project (specifically in the Adira case), the intermediary was perceived as not adding any real value compared to a direct connection between the intermediated companies. The persistence of supplier-supplier relationships outside the intermediary's influence is highly dependent on the widening of the interaction beyond the scope of the triad. For example, S1 (in Fig. 5) produces a part that is assembled together with other parts by S2 to form a component specified by or with the focal buyer. The activities and resources mobilized between S1 and S2 are dependent on their
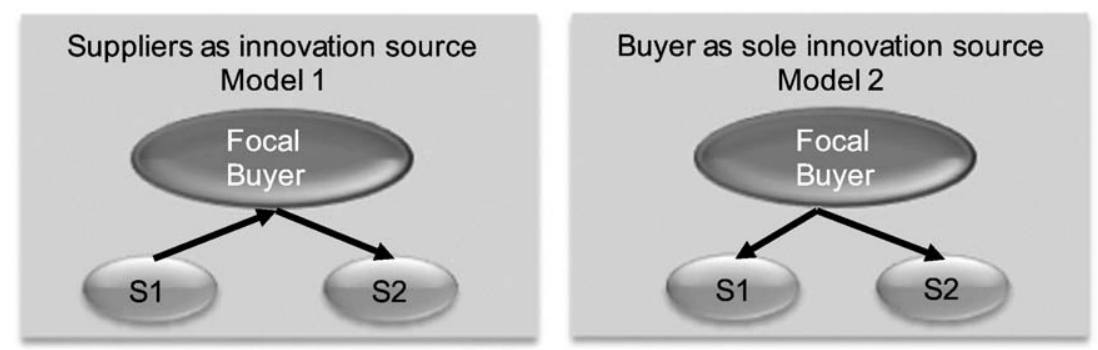

Fig. 4. Dynamics of relationships' cross-over effects (example of innovation effects). 


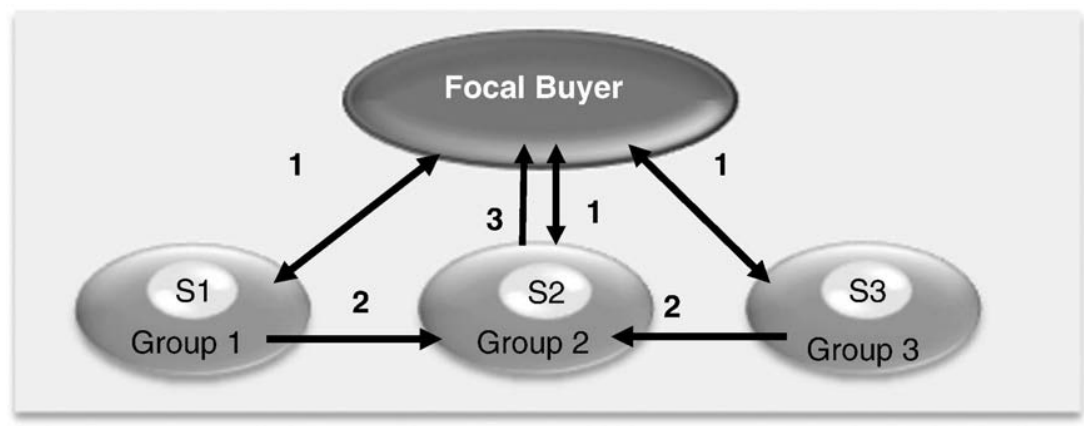

Fig. 5. Sequential triads.

respective relationships with the focal buyer. If the relationship between the focal buyer and S1 or S2 is broken, the dissolution of the connection between S1 and S2 will follow as it is solely based on the presence of the common buyer. This is a common event in one of the case studies, i.e. Vulcano transfers the assembly activities from one supplier to another and the relationships between the suppliers of the parts with the former 'assembler' are broken, and replicated with the new one. In the opposite direction, as GC's role was not restricted to the intermediation between Adira and Bosch-Rexroth, it was able to maintain the relationship (even if modified) with the focal buyer when the triad was dissolved.

These findings expose the strong dependence of direct suppliersupplier relationships on buyer-supplier dyads. As seen before, the creation of triads was mainly due to changes in the activities performed by some suppliers within those dyads. Thus, it seems reasonable to expect that further changes, namely, a deeper involvement and responsibility of suppliers in the development process, may require more intense contacts between them. In such a situation, suppliers will quite probably need to share or co-develop activities, e.g. designing and testing new components. In such cases, some of the existing serial triads may become group poliads (Havila et al., 2004) which require the bringing together of all the actors to develop shared activities. If this evolution proves to be positive to the suppliers involved in shared or co-developed activities, they may decide to replicate these arrangements in their relationships with other buyers.

\section{Conclusions and contributions}

\subsection{Summary of findings}

The individual and comparative analysis of the cases revealed three phenomena. Firstly, the management of supplier-supplier relationships within portfolios is not a major issue in the context of supplier management, as revealed in both case studies. Horizontal relationships between suppliers, with or without the intervention of the focal buyer, have limited relevance. This marginality of relationships between suppliers results from the perceptions of dyadic relationships as the most suitable mechanism to fulfill both buyers' and suppliers' goals. In fact, although suppliers are necessarily interdependent, that interdependence is embodied more in the cross-over effects of buyer-supplier dyads than in direct links between suppliers. While not evident in any of these cases, it is possible that a more active and strategic role of suppliers, e.g. a deeper involvement in new product development, may result in a higher prevalence and importance of direct relationships between suppliers and in the organization of these relationships in group poliads rather than in sequential triads. However, further research is needed to test this idea. Secondly, the dynamics of the diffusion of the effects of one buyer-supplier dyad to other dyads is conditioned by the roles actors play in those relationships and by the structures (e.g., interface characteristics) and content (e.g., functions) of those relationships.
Finally, as direct relationships between suppliers are rare and of limited effect in our case examples, the focal buyers exert a strong control over suppliers' interdependencies and seems to be able to manage them in a way that best suits their own goals and interests.

\subsection{Theoretical contributions}

This paper provides new insights into the structure and management of supplier portfolios, as well as on their dynamics and perceived impact by both the focal buyers and their suppliers. It also furthers the knowledge and understanding of firms' attitudes and actions in this field.

Firstly, the paper identifies a number of factors that contribute to the prevalence or absence of direct links between suppliers. It also highlights the process and dynamics of knowledge and innovation diffusion within supplier portfolios. The paper identifies buyersupplier dyads as the essential pillar both of the creation and management of direct relationships between suppliers, and of the management of cross-over effects of individual buyer-supplier relationships. Dyads between the focal buyer and its suppliers are the space reserved for the combination and development of the most valued resources, leaving to the supplier-supplier relationships the activities perceived as low-value and low-impact for their businesses. Buyer-supplier dyads are also important as their content and configuration condition the intensity and scope of cross-over effects.

The paper suggests that an excessive control on the buyer side makes it the single source of innovation, thereby restricting the possibility of exploring suppliers' innovation capabilities and replicating their effects in the portfolio. While dependency on buyers facilitates suppliers' compliance with the buyer demands, evidence was also found that in order to organize and mobilize actual interaction between indirect counterparts, the 'intermediator'/'mobilizer' must conciliate, or at least, not harm their interests and make itself valuable to them.

Finally, at a methodological level, by conducting a multi-level investigation (with the buyer-supplier dyadic level and the supplier portfolio/network level being central), it was possible to show a more holistic and integrative type of supplier management than previous studies have done. Specifically, the paper uncovers links between the dyadic and network levels, thereby enabling a degree of understanding and explanation of supplier network phenomena which provide rich ground for further research.

\subsection{Managerial contributions}

The findings of our case analysis stress the potential impact of supplier portfolios on the enhancement of focal buyers' performance. As such, clear managerial implications for practical activities result. Fostering the creation of direct relationships between suppliers and managing the resulting cross-over effects may result in a higher efficiency and innovation of both buyers and suppliers. However, 
managers must be aware of the fact that this potential is severely conditioned by the type of suppliers that firms work with and by what occurs in each dyadic relationships, e.g. the roles played by suppliers. If a set of efficient and innovative suppliers is a sine qua non condition to enhance the performance of all the actors involved, the focal buyer has a central role in diffusing and leveraging efficiency and innovation gains produced in individual relationships to other relationships within the portfolio. Being able to recognize the potential that resides in each supplier relationship and how its benefits can be multiplied by its diffusion to other relationships is undoubtedly a central task in the management of supplier portfolios.

\section{References}

Alderson, W., \& Martin, M. (1965). Toward a formal theory of transactions and transvections. Journal of Marketing Research, 2(2), 117-127.

Andersen, P., \& Kragh, H. (2010). Sense and sensibility: Two approaches for using existing theory in theory-building qualitative research. Industrial Marketing Management, 39(1), 49-55.

Araújo, L., Dubois, A., \& Gadde, L. -E. (1999). Managing interfaces with suppliers. Industrial Marketing Management, 28(5), 497-506.

Araújo, L., Dubois, A., \& Gadde, L. -E. (2003). The multiple boundaries of the firm. Journal of Management Studies, 40(5), 1255-1277.

Axelsson, B. (1992). Corporate strategy models and networks. In Björn Axelsson, \& Geoff Easton (Eds.), Industrial Networks: A New View of Reality. London: Routledge.

Bengtsson, M., \& Kock, S. (1999). Cooperation and competition in relationships between competitors in business networks. Journal of Business $\mathcal{E}$ Industrial Marketing, 14(3), 178-194.

Bensaou, M. (1999). Portfolios of buyer-suppliers relationships. Sloan Management Review, 40(4), 35-44.

Bogner, W., \& Thomas, H. (1993). The role of competitive groups in strategy formulation: A dynamic integration of two competing models. Journal of Management Studies, 30(1), 51-67.

Bonoma, T. (1985). Case research in marketing: Opportunities, problems and process. Journal of Marketing Research, 22, 199-208.

Casciaro, T., \& Piskorski, M. (2005). Power imbalance, mutual dependence, and constraint absorption: A closer look at resource dependence theory. Administrative Science, 50(2), 167-199.

Choi, T., \& Wu, Z. (2009). Triads in supply networks: Theorizing buyer-suppliersupplier relationships. Journal of Supply Chain Management, 45(1), 8-36.

Cousins, P., \& Spekman, R. (2003). Strategic supply and the management of inter- and intra-organisational relationships. Journal of Purchasing E' Supply Management, 9 (1), 19-29.

Dubois, A., \& Araújo, L. (2004). Research methods in industrial marketing studies. In Håkan Håkansson, Debbie Harrison, \& Alexandra Waluszewski (Eds.), Rethinking Marketing - Developing a New Understanding of Markets. Chichester: John Wiley \& Sons.

Dubois, A., \& Araújo, L. (2007). Case research in purchasing and supply management: opportunities and challenges. Journal of Purchasing E Supply Management, 13(3), $170-181$.

Dubois, A., \& Fredriksson, P. (2008). Cooperating and competing in supply networks: Making sense of a triadic sourcing strategy. Journal of Purchasing E Supply Management, 14(3), 170-179.

Dubois, A., \& Gadde, L. -E. (2002). Systematic combining: An abductive approach to case research. Journal of Business Research, 55, 553-560.

Dubois, A., Hulthén, K., \& Pedersen, A. -C. (2004). Supply chains and interdependence: A theoretical analysis. Journal of Purchasing \& Supply Management, 10(1), 19-29.

Dubois, A., \& Pedersen, A. -C. (2002). Why relationships do not fit into purchasing portfolio models - A comparison between the portfolio and industrial network approaches. European Journal of Purchasing \&' Supply Management, 8(1), 35-42.

Dyer, J., \& Hatch, N. (2004). Using supplier networks to learn faster.Sloan Management Review, 57-63 Spring.

Dyer, J., \& Nobeoka, K. (2000). Creating and managing a high-performance knowledgesharing network: The Toyota case. Strategic Management Journal, 21, 345-367.

Easton, G. (2010). Critical realism in case study research. Industrial Marketing Management, 39(1), 118-128.

Easton, G., \& Araújo, L. (1992). Non-economic exchange in industrial network. In Björn Axelsson, \& Geoff Easton (Eds.), Industrial Networks - A New View of Reality. London: Routledge.

Easton, G., Burrell, R., Rothschild, R., \& Shearman, C. (1993). Managers and competition. Oxford: Blackwell Business.

Fiegenbaum, A., \& Thomas, H. (1993). Strategic groups as reference groups: Theory, modeling, and empirical examination of industry and competitive strategy. Strategic Management Journal, 16(6), 461-476.

Ford, D., Gadde, L. -E., Håkansson, H., \& Snehota, I. (2003). Managing business relationships. Chichester: John Wiley \& Sons.

Ford, D., \& Håkansson, H. (2006). The idea of interaction. The IMP Journal, 1(1), 4-27.

Ford, D., \& McDowell, R. (1999). Managing business relationships by analysing the effects and value of different actions. Industrial Marketing Management, 28(5), $429-442$.
Foss, N. J., \& Loasby, B. (1998). Coordination and capabilities. In Nicolai J. Foss, \& Brian Loasby (Eds.), Economic Organization, Capabilities and Coordination: Essays in Honour of G. B. Richardson. London: Routledge.

Gadde, L. -E., \& Håkansson, H. (2001). Supply networks strategy. Chichester: John Wiley \& Sons.

Gattorna, J., \& Walters, D. (1996). Managing the supply chain: A strategic perspective. London: McMillan Press.

Gelderman, C. \& van Weele, A. (2002). Purchasing portfolios analysis: Towards a comprehensive model of conditions, goals and strategies based on explorative case studies. Proceedings of the 11th IPSERA Conference, Twente.

Gelderman, C., \& van Weele, A. (2005). Purchasing portfolio models: A critique and update.The Journal of Supply Chain Management, 19-28 Summer.

Håkansson, H., \& Ford, D. (2002). How should companies interact in business networks? Journal of Business Research, 55(2), 133-139.

Håkansson, H., Havila, V., \& Pedersen, A. -C. (1999). Learning in networks. Industrial Marketing Management, 28(5), 443-452.

Håkansson, H., \& Johanson, J. (1993). Industrial functions of business relationships. In S. Tammer Cavusgil, \& D. Deo Sharma (Eds.), Industrial Networks - Advances in International Marketing. New York: Jay Press.

Håkansson, H., \& Snehota, I. (1995). Developing relationships in business networks. London: Routledge.

Harland, C., Lamming, R., \& Cousins, P. (1999). Developing the concept of supply strategy. International Journal of Operations \& Production Management, 19(7), $650-674$.

Hartmann, E., Ritter, T., \& Gemünden, H. (2001). Determining the purchase situation: Cornerstone of supplier relationship management. Proceedings of the 17th IMP Conference, Oslo.

Havila, V., Johanson, J., \& Thilenius, P. (2004). International business-relationship triads. International Marketing Review, 21(2), 172-186.

Henneberg, S., Mouzas, S., \& Naudé, P. (2006). Network pictures - Concepts and representations. European Journal of Marketing, 40(3/4), 408-429.

Holmen, E., \& Perdersen, A. -C. (2003). Strategizing through analyzing and influencing the networking horizon. Industrial Marketing Management, 32(5), 409-418.

Jårvensivu, T., \& Törnroos, J. -A. (2010). Case study research with moderate constructionism: Conceptualization and practical illustration. Industrial Marketing Management, 39(1), 100-108.

Kraljic, P. (1983). Purchasing must become supply management.Harvard Business Review, 109-117 September.

Krapfel, R., Salmond, D., \& Spekman, R. (1991). A strategic approach to managing buyer-seller relationships. European Journal of Marketing, 25(9), 22-37.

Krippendorff, K. (2004). Content analysis. Thousand Oaks: Sage.

Loasby, B. (1998). The organization of capabilities. Journal of Economic Behavior and Organization, 35(2), 139-160.

Ma, X., Yao, X., \& Xi, Y. (2009). How do interorganizational and interpersonal networks affect a firm's strategic adaptive capability in a transition economy? Journal of Business Research, 62(11), 1087-1095.

Mota, J., \& de Castro, L. (2005). Relationship portfolios and capability development: Cases from the moulds industry. Journal of Purchasing \& Supply Management, 11(1), $42-54$.

Mouzas, S., \& Naudé, P. (2007). Network mobilizer. Journal of Business \& Industrial Marketing, 22(1), 62-71.

Nellore, R., \& Söderquist, K. (2000). Portfolio approaches to procurement: Analyzing the missing link to specification. Long Range Planning, 33(2), 245-267.

Olsen, R., \& Ellram, L. (1997). A portfolio approach to supplier relationships. Industrial Marketing Management, 26(2), 101-113.

Pfeffer, J., \& Salancik, G. (1978). The external control of organizations: A resource dependence perspective. New York: Harper and Row.

Phillips, J., Liu, B., \& Costello, T. (1998). A balance theory perspective of triadic supply chain relationships. Journal of Marketing Theory and Practice, 6(4), 78-91.

Ragin, C. (2000). Fuzzy-set social science. Chicago: The University of Chicago Press.

Richardson, G. (1972). The organization of industry. The Economic Journal, 82, 883-896.

Ritter, T., \& Ford, D. (2004). Interactions between suppliers and buyers in business markets. In Håkan Håkansson, Debbie Harrison, \& Alexandra Waluszewski (Eds.), Rethinking Marketing - Developing a New Understanding of Markets. Chichester: Wiley.

Sivadas, E., \& Dwyer, F. (2000). An examination of organizational factors influencing new product success in internal and alliance-based processes. Journal of Marketing, 64(1), 31-49.

Turnbull, P. (1990). A review of portfolio planning models for industrial marketing and purchasing management. European Journal of Marketing, 24(3), 7-22.

Turnbull, P., \& Zolkiewski, J. (1997). Profitability in buyer portfolio planning. In David Ford (Ed.), Understanding Business Markets, 2nd edition. . London: Dryder Press.

Wagner, S., \& Boutelier, R. (2002). Capabilities for managing a portfolio of supplier management.Nov-Dec: Business Horizons 79-88.

Wagner, S., \& Johnson, J. (2004). Configuring and managing strategic supplier portfolios. Industrial Marketing Management, 33(8), 717-730.

Zolkiewski, J., \& Turnbull, P. (2000). Relationship portfolios - Past, present and future. Proceedings of the 16th IMP Conference, Bath.

Zolkiewski, J., \& Turnbull, P. (2002). Do relationship portfolios and networks provide the key to successful relationship management? Journal of Business \& Industrial Marketing, 17(7), 575-597. 